\title{
Intercomparison of oceanic and atmospheric forced and coupled mesoscale simulations
}

\author{
Part I: Surface fluxes

\begin{abstract}
P. Josse, G. Caniaux, H. Giordani, S. Planton
Météo France, Centre National de Recherche Météorologique, 42 Av. G. Coriolis, 31057 Toulouse Cedex, France, Fax: 335.61.07.8209, e-mail: patrick.josse@meteo.fr
\end{abstract}

Received: 26 June 1998 / Revised: 16 October 1998 / Accepted: 4 November 1998

\begin{abstract}
A mesoscale non-hydrostatic atmospheric model has been coupled with a mesoscale oceanic model. The case study is a four-day simulation of a strong storm event observed during the SEMAPHORE experiment over a $500 \times 500 \mathrm{~km}^{2}$ domain. This domain encompasses a thermohaline front associated with the Azores current. In order to analyze the effect of mesoscale coupling, three simulations are compared: the first one with the atmospheric model forced by realistic sea surface temperature analyses; the second one with the ocean model forced by atmospheric fields, derived from weather forecast re-analyses; the third one with the models being coupled. For these three simulations the surface fluxes were computed with the same bulk parametrization. All three simulations succeed well in representing the main oceanic or atmospheric features observed during the storm. Comparison of surface fields with in situ observations reveals that the winds of the fine mesh atmospheric model are more realistic than those of the weather forecast re-analyses. The low-level winds simulated with the atmospheric model in the forced and coupled simulations are appreciably stronger than the re-analyzed winds. They also generate stronger fluxes. The coupled simulation has the strongest surface heat fluxes: the difference in the net heat budget with the oceanic forced simulation reaches on average $50 \mathrm{Wm}^{-2}$ over the simulation period. Sea surface-temperature cooling is too weak in both simulations, but is improved in the coupled run and matches better the cooling observed with drifters. The spatial distributions of sea surface-temperature cooling and surface fluxes are strongly inhomogeneous over the simulation domain. The amplitude of the flux variation is maximum in the coupled run. Moreover the weak correlation between the cooling and heat flux patterns indicates that the surface fluxes are not responsible for the whole cooling and suggests that the response of the ocean mixed layer to the atmosphere is highly non-local and enhanced in the coupled simulation.
\end{abstract}

Key words. Oceanography: physical (air-sea interaction; eddies and mesoscale processes). Meteorology and atmospheric dynamics (ocean-atmosphere interactions)

\section{Introduction}

Air-sea interactions are of major interest because they play a key role in the modeling of either forced oceanic and atmospheric circulation, or coupled ocean-atmosphere systems. These interactive processes at the air-sea interface cannot be dissociated from the physics of the marine atmospheric boundary layer (hereafter MABL) and the oceanic mixed layer (hereafter OML).

Results from several experiments (JASIN, Joint AirSea Interaction experiment (Pollard, 1978); FASINEX, Frontal Air-Sea Interaction Experiment (Stage and Weller, 1985); SEMAPHORE (Structure des Echanges Mer Atmosphère, Propriétés des Hétérogénéités Océaniques, Recherche Expérimentale; Eymard et al., 1996) CEI: 1996 indicate that the heterogeneity of atmospheric forcing and of oceanic surface conditions has contrasting effects on both boundary layers. For instance, the variation of sea surface-temperature (SST) associated with oceanic fronts has an impact on the structure of the MABL. SST gradients modify the horizontal distribution of air-sea fluxes (Khalsa et al., 1989; Friehe et al., 1991). An acceleration of the wind has frequently been observed on the warm side of oceanic fronts in response to stronger turbulent heat fluxes (Sweet et al., 1981, Kwon et al., 1998). However, this acceleration is not systematic, as shown by Weller et al., 1995. A consequence of these surface inhomogeneity is the existence of mesoscale atmospheric circulations (Doyle and Warner, 1990), the evidence of which is difficult to assess because these circulations are generally embedded in the large scale atmospheric circulation (Giordani et al., 1998). 
From the oceanic point of view, the oceanic response to the inhomogeneity of the atmospheric events is very important in modifying the OML: deepening of the mixed layer is generally associated with wind events (Bane and Osgood, 1989). Cold air outbreaks may induce some change in the circulation of deep oceanic fronts as suggested by Adamec and Elsberry (1985a, 1985b), Nof (1983) or Huang (1990). More recently Caniaux and Planton (1998) analyzed the response of an oceanic front to a strong storm documented during the SEMAPHORE experiment and found that, during this experiment lasting one month, most of the evolution of the oceanic mixed layer occurred during this short time event. Moreover the response of the OML to this storm was not the same on each side of the front. Feedbacks are possible, through the resulting changes in ocean mixing and energy transfer that eventually change the sea surface temperature and act on the MABL.

The SEMAPHORE experiment IOP (Intensive Observing Period) was conducted from mid-October to mid-November in the northeast Atlantic between the Azores and Madeira archipelagoes, in the region of a quasi-permanent thermohaline front. This experiment was devoted to the study of mesoscale oceanic circulation and to air-sea interactions. The experimental investigation was achieved using floats and ship hydrologic surveys. Thus, three research vessels, drifting buoys sampled a $500 \mathrm{~km} \times 500 \mathrm{~km}$ square oceanic domain, and atmospheric measurements were taken onboard ship and aircrafts. This extended data set allowed to simulate quite realistically the behaviour of the MABL above the Azores front with an atmospheric mesoscale model and the response of the OML to atmospheric events with an oceanic mesoscale model. The results of these two forced runs (i.e., non coupled models) are respectively analyzed in Giordani et al. (1998) and Caniaux and Planton (1998). These models were separately constrained at the surface with what was thought to be the best oceanic (respectively atmospheric) forcing. A next step in the analyses of the interaction of the MABL and OML in the frame of the SEMAPHORE experiment was to run a coupled mesoscale oceanic-atmospheric model. In order to better document the strong evolution of the OML simulated by the oceanic model, the above mentioned storm event was simulated again with this coupled model. The aim of the present study is to compare the surface fluxes obtained from three mesoscale simulations of the same event: a forced oceanic simulation, a forced atmospheric simulation and the coupled simulation. The first section briefly describes the numerical tools and the coupler used for the third simulation. A description of the flux parametrization used is also given. The main features of the atmospheric and oceanic simulations are presented in the second section. In the third one, the realism of the three simulations is analyzed. The fluxes are compared and the observed differences are discussed and interpreted in Section 4.

\section{Numerical tools and bulk parametrization}

\subsection{The atmospheric model}

\section{General features}

The atmospheric model used is a non-hydrostatic research model (Méso-NH model) which has been developed by Météo-France (Centre National de Recherches Météorologiques, Toulouse) and the Centre National de la Recherche Scientifique (Laboratoire d'Aérologie, Toulouse). This model is able to simulate atmospheric motions from the micro-scale up to the meso-scale and a comprehensive physical package is available. The numerous functionalities available in the Méso-NH atmospheric simulation system are detailed in Lafore et al. (1998). The version used in this study includes a one-and-a-half-order turbulence closure scheme (Cuxart et al., 1995), a warm microphysics parametrization (Kessler, 1969) and a deep convection parametrization following Kain and Fritsch (1993). The ECMWF radiation scheme (Morcrette, 1989) has been interfaced with the model. The model includes 43 levels on the vertical and a stretched vertical coordinate is used in order to give a fine resolution in the lower levels (21 levels describe the first layers from the surface up to $2500 \mathrm{~m})$. The horizontal grid $(10 \mathrm{~km})$ has been chosen the same as for the oceanic model, in order to avoid useless horizontal interpolations. The time step is $30 \mathrm{~s}$.

\section{Initialization and lateral forcing}

A powerful capability of the Méso-NH model is that it may be initialized from 3-dimensional atmospheric fields issued from the operational forecast model ARPEGE used by the French meteorological weather service (Météo-France). Specific re-analyzed atmospheric and SST fields were produced for the SEMAPHORE experiment by Giordani et al. (1998) from a version of this operational model every $6 \mathrm{~h}$. This version is a T119 spectral truncation, with a varying resolution corresponding to a stretching factor of 3.5. The pole of stretching is located in the centre of the SEMAPHORE domain $\left(34^{\circ} \mathrm{N}, 23^{\circ} \mathrm{W}\right)$, allowing a good resolution over the experiment area (near $30 \mathrm{~km})$. Comparison between re-analyzed and observed data reveals a good agreement. These re-analyzed fields were thus used to initialize the Méso-NH model and to force it at its lateral boundaries. At the lateral boundaries, the large scale fields are used for the scalars, including the tangential velocity component, and a general Sommerfeld equation proposed by Carpenter (1982) is used for the normal velocity component.

To prescribe the large-scale evolution, a newtonian relaxation towards the large scale fields is applied in a sponge zone near the boundaries (the five outermost points) to both dynamical and thermodynamical variables.

Some modifications were implemented in the model in order to adapt it for the first time to the OASIS 
coupler. A few message-passing routines were added, as well as a temporal averaging for the fluxes between two coupling events. The surface fluxes are calculated by the atmospheric model at every time step (30 s) and are averaged over a coupling period (900 s).

\subsection{The oceanic model}

\section{General features}

The model is the mesoscale version of the primitive equation model OPA developed at the LODYC (Laboratoire d'Océanographie Dynamique et de Climatologie, Paris; Andrich et al., 1988). This general circulation model has been adapted to the mesoscale by Caniaux et al. (1993), with improved horizontal and vertical resolution, that is $10 \mathrm{~km} \times 10 \mathrm{~km}$ on the horizontal and $5 \mathrm{~m}$ for the vertical grid spacing in the OML, stretched to $170 \mathrm{~m}$ at the bottom. This version also includes open lateral boundaries based on the Davies (1976) scheme and a 1.5 order turbulence closure scheme implemented by Blanke and Delecluse (1993).

The version of the mesoscale oceanic model used includes two new developments. The first one is the introduction of a parametrization of the diapycnal mixing through the thermocline (Large et al., 1994). This parametrization allowed to better simulate the deepening of the OML associated with strong wind events (Josse et al., 1996; Caniaux et al., 1996). A second change was introduced in the model specifically for the coupling with the MESO-NH model. The only geographical system available for the atmospheric model is the conformal projection. In consequence, the horizontal grid of the oceanic model, which was formerly developed on a spherical grid, had to be turned to a conformal plane in order to be conservative with respect to the surface fluxes. Thus for both uncoupled and coupled simulations, the horizontal grid is $10 \mathrm{~km} \times 10 \mathrm{~km}$ on the conformal plane. Finally, the model has a horizontal extent of a $\sim 500 \mathrm{~km}(45 \times 45$ points) and includes 49 levels on the vertical, down to $2000 \mathrm{~m}$. The oceanic time step has been chosen equal to $900 \mathrm{~s}$.

\section{Initialization and lateral forcing}

The extended oceanic dataset collected during the IOP allows the detailed initialization of a mesoscale model. These data (temperature and salinity) were analyzed by optimal interpolation on a $\left(27^{\circ} \mathrm{W}-20^{\circ} \mathrm{W}, 31^{\circ} \mathrm{N}-37^{\circ} \mathrm{N}\right)$ domain that is larger than the simulation one (Caniaux and Planton, 1998). Two oceanic states are available: one for 20 October and the other for the 11 November. In addition to this, re-analyses have been performed for the upper $150 \mathrm{~m}$ (the 29 MARISONDE GT drifters provided temperature soundings down to $150 \mathrm{~m}$ ). These fields are available at $00 \mathrm{~h}$ every day.

For our purpose, two oceanic 3-D fields are needed: 28 October and 1 November. These fields were obtained in two steps. First, a temporal interpolation between 20 Oct and 11 Nov was performed. The resulting fields in the 21 upper levels have been replaced by the corresponding daily re-analysis, with a smooth transition towards $150 \mathrm{~m}$ to ensure continuity. This initial mass field was used to initialize the current field through geostrophic approximation.

The treatment of the open lateral boundaries is one of the difficulties in modelling a limited area of ocean. It consists in a Newtonian relaxation applied in a damping zone near the boundary. A prognostic variable $\mathrm{X}$ is forced to relax toward a large scale data field by the addition of a tendency term:

$\partial_{t} X=-K(i) \times\left(X-X_{l s}(i)\right)$

The damping coefficient $K(i)$ varies with the distance $i$ from the boundary. The large-scale field $X_{l s}$ is temporally interpolated between the initial and final analyses at each time step. The relaxation is applied to the five outermost points of the simulation domain, and only to the tracer equations (temperature and salinity). The area not affected by the relaxation at the lateral boundaries is thus $350 \mathrm{~km} \times 350 \mathrm{~km}(21.6 \mathrm{~W}-25.4 \mathrm{~W}, 32.5 \mathrm{~N}-35.5 \mathrm{~N})$. Currents on the lateral boundaries are deduced from geostrophy, using the large scale mass field.

\subsection{The coupler and the coupling technique}

The version 2.0 of the OASIS coupler has been used to achieve the coupling of the two models above. This coupler was developed by the CERFACS (Centre Européen de Recherche et de Formation Avancée en Calcul Scientifique, Toulouse) and is widely used for the coupling of GCMs (Terray et al., 1998). The coupler allows synchronous running of the two models and eight variables are exchanged: SST, latent and sensible heat fluxes, precipitation rate, shortwave and longwave radiation and the two components of the stress. The latent and sensible heat fluxes were not gathered in a non-solar heat flux because the latent heat flux is used by the oceanic model to calculate the interface condition for salinity (evaporation).

For the coupled simulation, the coupling frequency has been chosen equal to the oceanic timestep. The two models exchange fluxes and SST 96 times a day at every grid point.

For our purpose, it is worth noticing that the models being coupled are separate entities. They are unchanged with respect to their own main options compared to the uncoupled mode. The only difference is the boundary condition at the ocean-atmosphere interface (i.e. the sea surface-temperature or the low-level atmospheric parameters).

\subsection{The bulk parametrization}

In the present study, three mesoscale simulations of the same four-day period (see Section 3.1) have been performed: a forced oceanic simulation, a forced atmospheric one and a coupled one. A high consistency 
is needed in the air-sea fluxes calculation method in the different simulations to achieve a fair comparison of the fluxes. In the coupled model, a bulk parametrization is used to calculate the fluxes at the air-sea interface from oceanic and atmospheric variables. Hence the surface condition for the oceanic forced run had to be set by atmospheric parameters rather than turbulent fluxes. Symmetrically, for the atmospheric model a SST is prescribed as a lower boundary condition.

For the sake of comparison of the surface fluxes, the implementation of the same bulk parametrization in the two models for the three simulations is required. For that reason, we chose the bulk flux parametrization derived from the SEMAPHORE experiment by Dupuis et al. (1997). This parametrization is well suited for low to medium wind velocities. For higher wind velocities, the parametrization of the wind stress is derived from the Yelland and Taylor (1996) formulae. Thus, the bulk transfer coefficients in neutral conditions $C d_{n}, C h_{n}, C e_{n}$ (respectively for momentum, sensible heat and water vapour) are calculated iteratively from the sea surface temperature and atmospheric parameters at a level close to the surface. For this purpose, expressions of the transfer coefficients as a function of the average wind at a reference height of $10 \mathrm{~m}$ in neutral conditions (U 10n) are needed. The following formulae are used $\left(C e_{n}=C h_{n}\right)$ :

$$
\begin{array}{lc}
C h_{n} \times 10^{3}=2.79 \times U_{10 n}^{-1}+0.66 & U_{10 n}<5.2 \mathrm{~m} / \mathrm{s} \\
C h_{n} \times 10^{3}=1.2 & U_{10 n}>5.2 \mathrm{~m} / \mathrm{s} \\
C d_{n} \times 10^{3}=11.7 \times U_{10 n}^{-2}+0.668 & U_{10 n}<5.5 \mathrm{~m} / \mathrm{s}
\end{array}
$$

For higher wind speeds $\left(U_{10 n}>5.5 \mathrm{~m} / \mathrm{s}\right)$, the Yelland and Taylor (1996) formulation is used:

$C d_{n} \times 10^{3}=0.07 \times U_{10 n}+0.6$

The atmospheric run is forced by a prescribed timedependent SST and the fluxes are calculated using the prognostic atmospheric variables (pression, temperature, water vapour mixing ratio, zonal and meridional wind) at the lowest calculation level. The oceanic run is

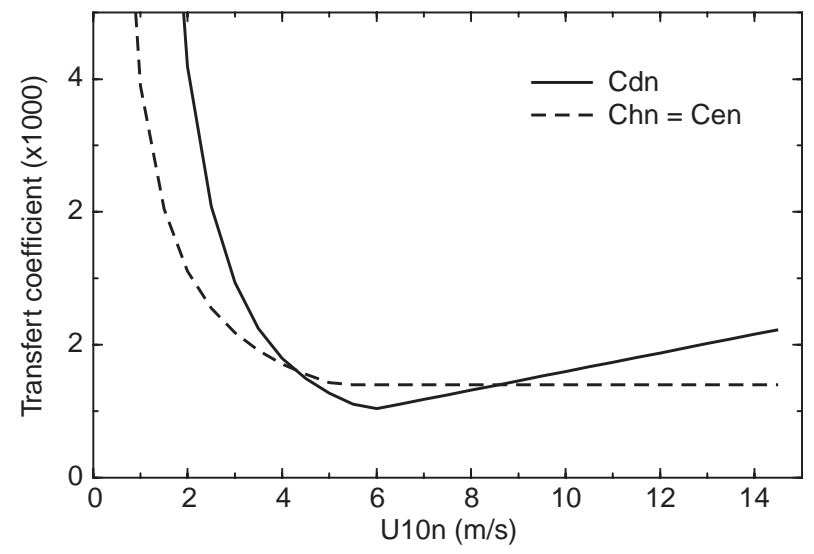

Fig. 1. Transfer coefficients as a function of $U_{10 n}$. The threshold values for the smooth flow regime and for the rough flow regime are $5.2 \mathrm{~m} / \mathrm{s}$ for $C_{h n}$ and $C_{e n}$ and $5.5 \mathrm{~m} / \mathrm{s}$ for $C_{d n}$ forced by prescribed time-dependent atmospheric parameters and the prognostic SST is used to calculate the turbulent fluxes. For the coupled run, both the prognostic SST and the prognostic atmospheric variables are used.

\section{The simulations}

\subsection{The cases studied}

In order to determine a possible impact of the coupling on the exchanges, we chose to simulate the period of the experiment when the interaction between the atmosphere and the ocean is potentially the highest. This period corresponds to the occurrence of the strongest storm which was documented during the experiment. An active low pressure was located just south of the domain on 28 October. Between 28 and 30 October it moved northeastward and the pressure in its center decreased from $1005 \mathrm{hPa}$ to $985 \mathrm{hPa}$ on 30 October. Then it increased to reach $1000 \mathrm{hPa}$ on 1 November (Fig. 2).

This meteorological situation generated strong northwesterly winds for 3 days over the simulation domain, with maxima reaching up to $20 \mathrm{~ms}^{-1}$. It worth noticing that, due to the synoptic structure, the wind direction remained unchanged during at least two days over the simulated area. As noted by Caniaux and Planton (1998) the resulting effects on sea surface-temperature and mixed layer deepening were strong, the cooling/deepening was almost as intense during these two days as during the rest of the one and a half month of the SEMAPHORE experiment.

Consequently, the three mesoscale simulations were performed on a four-day period from 28 October $(00 \mathrm{~h})$ to 1 November $(00 \mathrm{~h})$, covering the lifetime of the storm within the simulated domain.

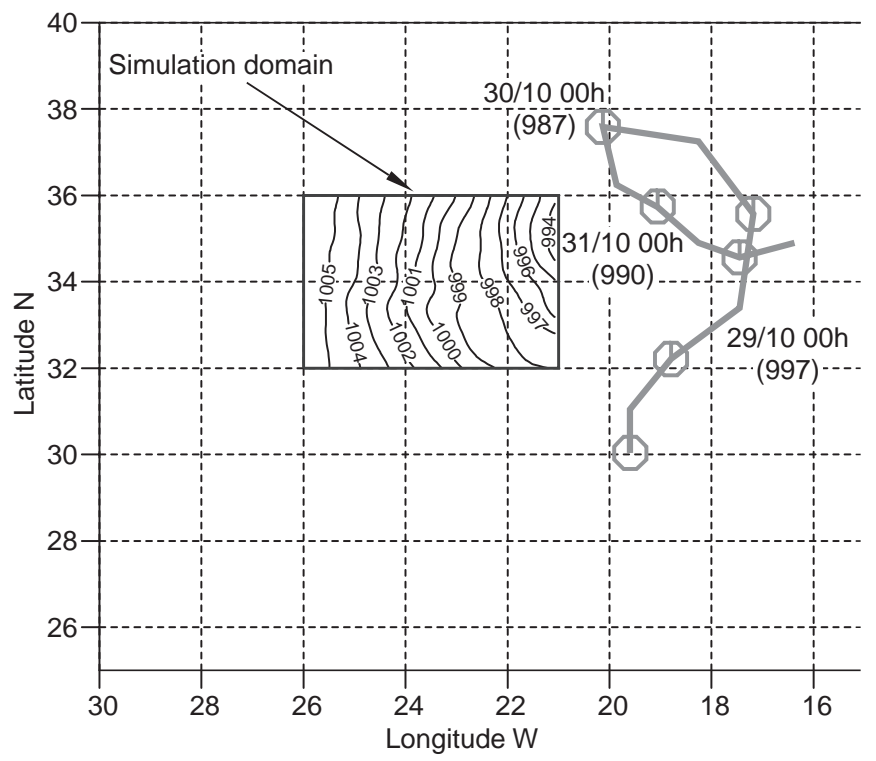

Fig. 2. Trajectory of the center of the pressure low between 27 October and 1 November. The analyzed sea level pressure field is displayed in the simulation domain for the 30 Oct $1800 \mathrm{~h}$ 
For the oceanic forced run, shortwave and longwave radiation fluxes were derived from the geostationary METEOSAT satellite fluxes collected at the Centre de Météorologie Spatiale (Météo France, Lannion), sampled hourly on a $0.04^{\circ}$ and $0.08^{\circ}$ grid respectively (Brisson et al., 1994). The fields have been area-averaged to be located on the wider model grid and linearly time interpolated at each time step. The atmospheric parameters required to calculate the surface fluxes are provided by the above mentioned re-analysis of the SEMAPHORE dataset. The SST of this re-analysis is gives the lower boundary condition of the atmospheric forced run.

\subsection{Validation}

The atmospheric variables at the lowest Méso-NH vertical level are used to calculate the fluxes in both the forced and the coupled atmospheric simulations. The pressure, temperature and water vapour fields have been averaged over the simulation domain every $2 \mathrm{~h}$ (every $6 \mathrm{~h}$ for the re-analyzed fields), and their evolution is shown Fig. 3.

The atmospheric model succeeds well in representing the general evolution of the thermodynamical variables. The pressure is minimum over the simulation domain on 30 October. A noticeable point about Fig. 3 is that the
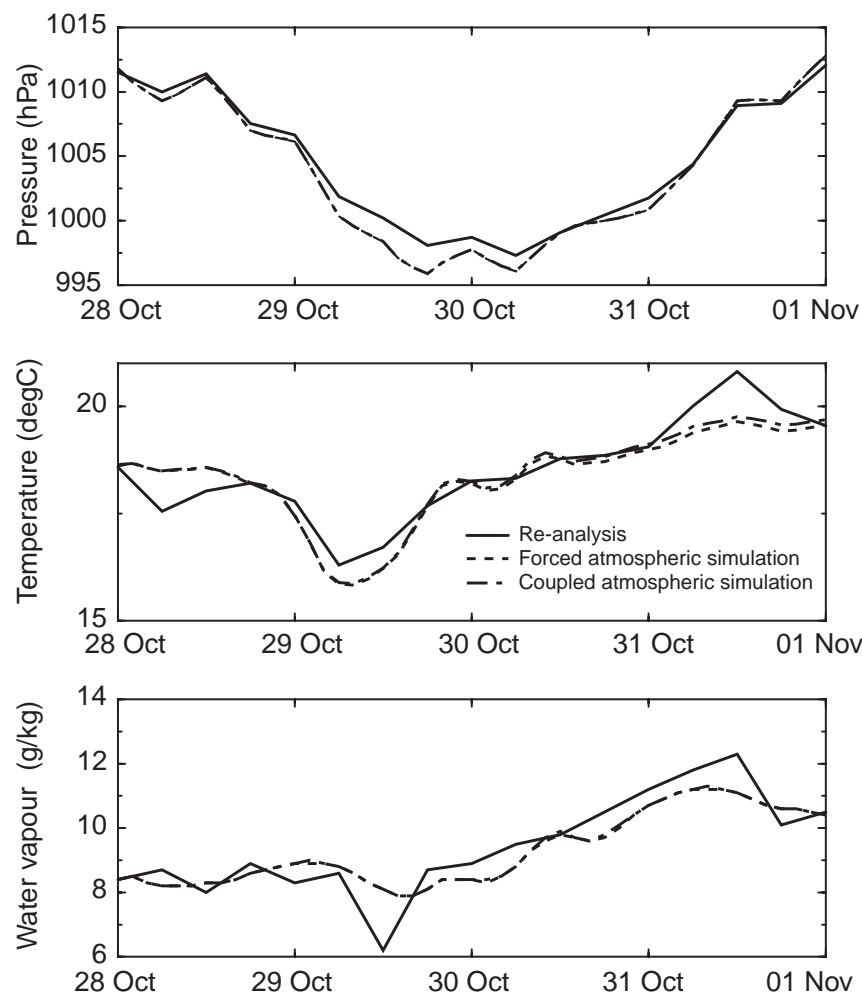

Fig. 3. From top to bottom: evolution of pressure, temperature and water vapour mixing ratio averaged on the simulation domain at the lowest Meso-NH vertical level $(20 \mathrm{~m})$. ARPEGE re-analysis (solid line), forced Meso-NH simulation (dotted line) and coupled Meso-NH simulation (dashed line) coupled and forced atmospheric simulations give very similar spatially averaged results even though some differences can be found locally. This is not surprising, since in this kind of atmospheric situation, large-scale effects are strong, and probably dominant. Moreover, from the atmospheric point of view, the only difference between the two simulations is the SST field used to calculate the turbulent fluxes: the large scale forcing at the lateral boundaries is the same.

The same evolution for the wind (Fig. 4) shows that the 2 days of strong northwesterly winds (29/30 Oct) are well represented by the atmospheric model, as well as the maximum wind for 30 October. The Meso-NH winds appear to be a little stronger than the re-analyzed winds, with a difference that reaches $3 \mathrm{~m} / \mathrm{s}$ on 4 October. This difference is likely to have an impact on the turbulent fluxes.

From the re-analyzed SST fields, a cooling of $0.75{ }^{\circ} \mathrm{C}$ is associated with the storm event (see Fig. 5). The simulated cooling is too weak, for both the coupled and the forced oceanic simulations: $0.35^{\circ}$ for the forced run and near $0.5^{\circ}$ for the coupled run. A first hypothesis for this feature can be a bias in the surface net heat flux. The
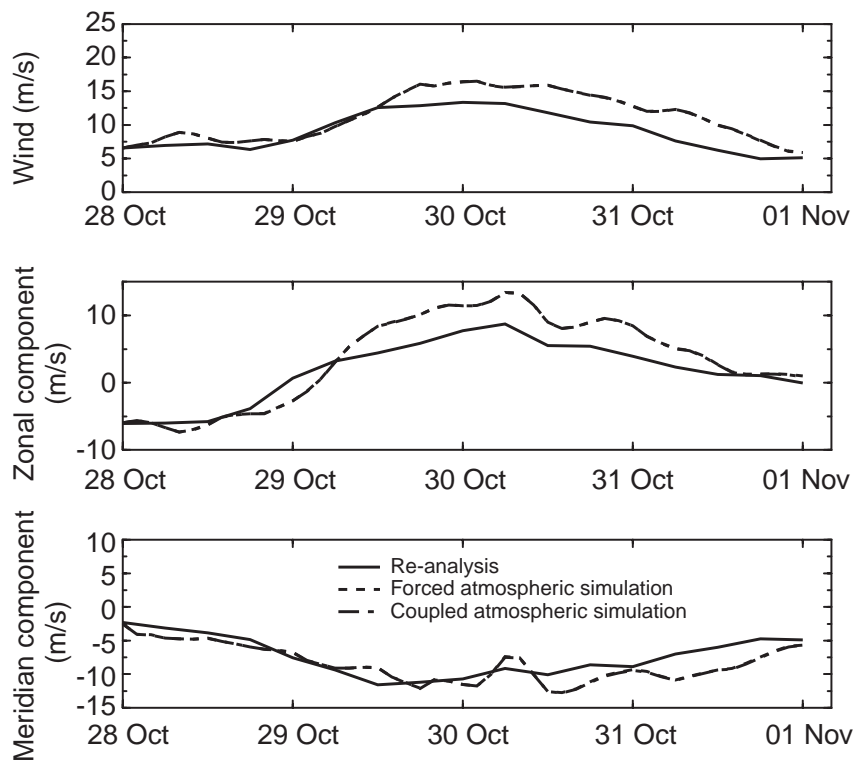

Fig. 4. From top to bottom: evolution of horizontal wind, zonal and meridional wind averaged on the simulation domain at the lowest Meso-NH vertical level $(20 \mathrm{~m})$. ARPEGE re-analysis (solid line), forced Meso-NH simulation (dotted line) and coupled Meso-NH simulation (dashed line)

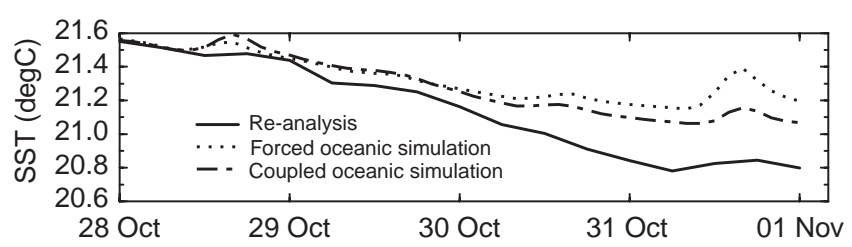

Fig. 5. Evolution of the sea surface temperature from 28 October to 1 November. ARPEGE re-analysis (solid line), forced OPA simulation (dotted line) and coupled simulation (dashed line) 
bulk parameterization (Dupuis et al., 1997) we used is well suited for low to medium wind velocities, but recent results from the CATCH (Couplage avec l'Atmosphère en Conditions Hivernales) seem to indicate that the turbulent fluxes for higher wind velocities are too weak (H. Dupuis, personal communication).

This weakness of the simulated cooling can also be related to an insufficient mixing at the bottom of the oceanic mixed layer, which can be due to the prescribed winds or more probably to the model itself. The introduction of the diapycnal mixing in the model had a noticeable effect (compared to other forced simulations of the same event, as indicated by sensitivity experiments), but a more detailed representations of the effect of the internal waves generated by the storm event (Eymard et al., 1996) is likely to improve the vertical mixing at the bottom of the mixed layer.

Other validation tests compared the simulated SST and winds to the MARISONDE GT drifters data. 29 MARISONDE GT drifters have been used during the IOP and ten of them remained in the $350 \times 350 \mathrm{~km}$ domain during all the simulation. The simulated 20-n winds have been extrapolated to $2.5 \mathrm{~m}$, the height of the anemometer on the MARISONDE GT drifting buoy using the stability functions of the bulk parameterization (Dupuis et al., 1997). For each MARISONDE drifter, measurements of SST and wind speed are available every $2 \mathrm{~h}$. The analyzed and simulated variables have been spatially and temporally interpolated on to the buoys trajectories and then averaged on the 10 drifters. Their temporal evolution is shown Fig. 6. As previously noted, the simulated cooling of the superficial ocean is still too weak, but the comparison to the buoy data demonstrates the ability of the oceanic model to reproduce satisfactorily the diurnal cycle. The simulated diurnal warming seems more realistic for the uncoupled
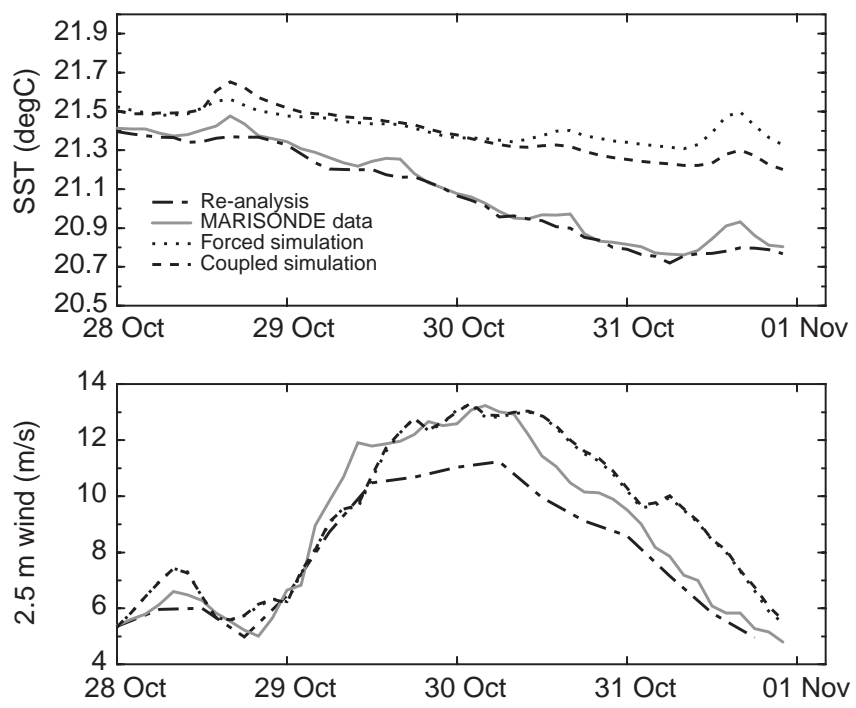

Fig. 6. From top to bottom: evolution of horizontal wind, zonal and meridional wind averaged on the simulation domain at the lowest Meso-NH vertical level $(20 \mathrm{~m})$. ARPEGE re-analyses (solid line), forced Meso-NH simulation (dotted line) and coupled Meso-NH simulation (dashed line) simulation. This is probably a consequence of the good quality of the METEOSAT radiative dataset used to force the uncoupled simulation.

As far as the 2.5 wind speed is concerned, both the coupled and uncoupled Méso-NH winds are in good agreement with the MARISONDE data. By contrast, the re-analyzed winds are too weak by $2 \mathrm{~ms}^{-1}$ : it seems that the observed $2.5-\mathrm{m}$ winds have been assimilated at first level of the ARPEGE model $(17 \mathrm{~m})$. Besides MARISONDE data were assimilated in a temporal radius of three hours around the analysis time. Since there is no temporal structure function in the ARPEGE system, all the data were assimilated with the same temporal weight. This point can explain the temporal switch of the re-analysis (and hence of the simulations forced by the re-analysis) compared to the observations. Besides, the decrease of the wind speed is too slow and the simulated winds are therefore too strong at the end of the stimulation. However, it remains that, when initialized and forced at its lateral boundaries by the reanalyzed winds, the Méso-NH model generates stronger winds which are in better agreement with the available observations.

Finally, this validation using spatially averaged parameters indicates that the Méso-NH model succeeds well in reproducing the temporal evolution of the thermodynamical variables needed to calculate the fluxes. The comparison with the MARISONDE data shows that the winds generated by the mesoscale model are in good agreement with the in-situ measurements, whereas the re-analyzed winds are too weak by $2 \mathrm{~ms}^{-1}$ during the strong wind period. The oceanic model represents the diurnal cycle for SST, but the cooling of the superficial ocean over the period is too weak. The better results of the coupled simulation can probably be related to the stronger winds in this case, inducing more deepening and stronger cooling as discussed in the next Section.

\section{Fluxes comparison}

\subsection{General comparison and temporal evolution}

Four sets of ocean-atmosphere fluxes are available for the comparison: the fluxes provided by the three simulations and the fluxes calculated from the reanalyzed SST and atmospheric parameters using the bulk parameterization presented in section 2.4. For convenience, these last fluxes will be hereafter referred to as re-analyzed fluxes.

The spatially and temporally averaged surface fluxes are summarized in Table 1.

In Fig. 7, the non solar heat flux (latent + sensible + net infrared), the solar heat flux and the momentum flux have been spatially averaged and then integrated over the four-day period. Since $\mathrm{Wm}^{-2}$ are more convenient than $\mathrm{Jm}^{-2}$, the integrated fluxes were divided by the duration of the simulation. The value at the end of the simulation thus corresponds to the average flux during the four days. 
Table 1. Simulated and 're-analyzed' surfaces fluxes

\begin{tabular}{lllll}
\hline & Re-analysis & $\begin{array}{l}\text { Forced } \\
\text { ocean }\end{array}$ & $\begin{array}{l}\text { Forced } \\
\text { atmosphere }\end{array}$ & Coupled \\
\hline Latent heat & -207 & -212 & -242 & -252 \\
Sensible heat & -36 & -38 & -42 & -44 \\
Net infrared & -36 & -36 & -31 & -30 \\
Solar & 112 & 112 & 106 & 103 \\
Total & -167 & -174 & -209 & -223 \\
Stress & 0.13 & 0.13 & 0.20 & 0.21 \\
\hline
\end{tabular}

The total heat fluxes from the forced oceanic simulation and the re-analyses are very similar: -167 and $-174 \mathrm{Wm}^{-2}$ after four days. The only difference in the fluxes calculation is indeed the sea surface temperature and the order of magnitude of the difference between the simulated and the re-analyzed SST is a few tenths of a degree.

The forced and coupled atmospheric simulations give about the same total heat flux with cumulated value of respectively -209 and $-223 \mathrm{Wm}^{-2}$. These values are stronger than the re-analysis ones by more than $40 \mathrm{Wm}^{-2}$. This difference can be related to the stronger winds simulated by Méso-NH. The little difference between the forced and coupled atmospheric simulations indicates the importance of the large scale atmospheric forcing in this kind of meteorological situation:
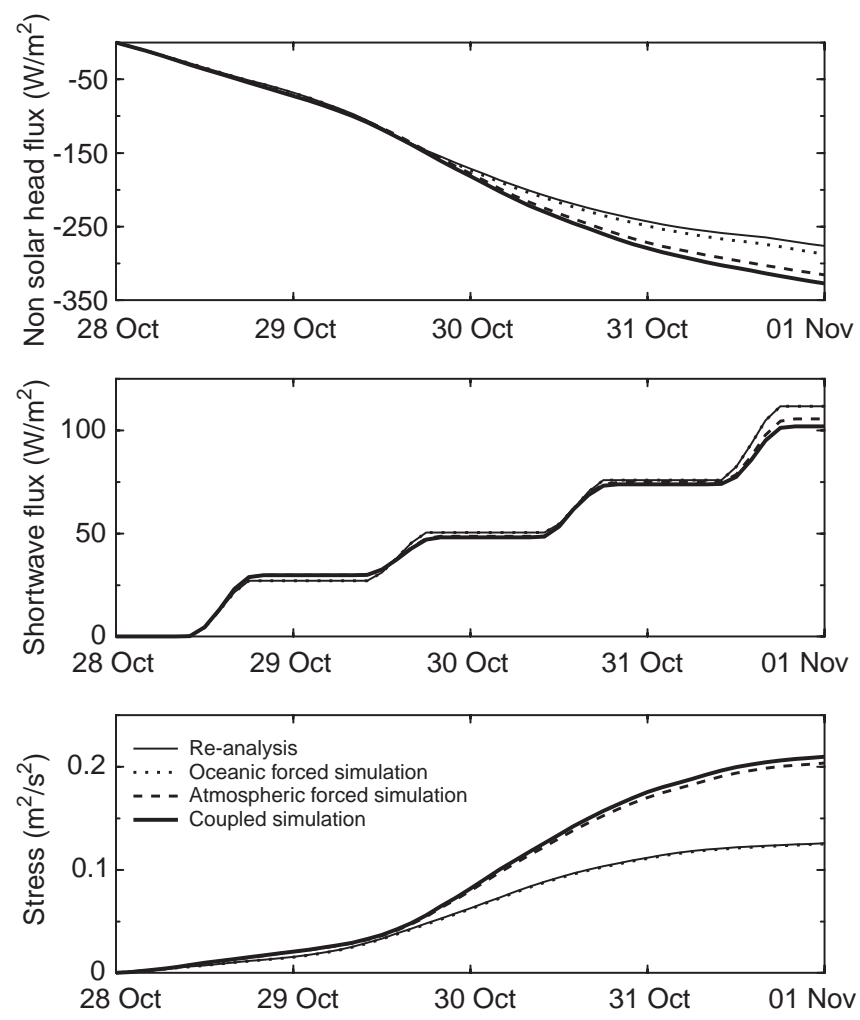

Fig. 7. From top to bottom: evolution of non-solar heat flux, shortwave flux and stress averaged on the simulation domain. Fluxes from ARPEGE re-analyses (solid), forced oceanic simulation (dotted) forced atmospheric simulation (dashed) and coupled simulation (dotdashed) the evolution of the atmosphere in the simulation domain is mostly imposed by the large scale information transmitted to the model via the lateral open boundaries. The modulation of this evolution by mesoscale effects appears to be weak on average over the domain. The warmer sea surface temperature (and hence greater thermal contrast between ocean and atmosphere) and the slightly stronger winds in the coupled simulation are probably responsible for the difference between the two Méso-NH simulations $\left(14 \mathrm{Wm}^{-2}\right)$.

By contrast, the forced and coupled oceanic simulations give appreciably different surface fluxes. The total heat fluxes are respectively -174 and $-223 \mathrm{Wm}^{-2}$. The two simulations give similar surface fluxes during the two first days (Fig. 7). The average nonsolar heat fluxes differ by only $10 \mathrm{Wm}^{-2}$ on 30 October. The difference appears when the winds and hence the fluxes are maxima. Both the net longwave and shortwave radiative fluxes of the coupled simulations are in good agreement with the METEOSAT fluxes used for the forced oceanic simulation. This dataset proved to be in good agreement with in situ measurements (Brisson et al., 1996). It shows that the radiative scheme used in the Méso-NH model succeeds well in representing the spatially averaged radiative fluxes at the surface. The difference $\left(50 \mathrm{Wm}^{-2}\right.$ for the net heat flux) comes mostly from the latent heat flux $\left(40 \mathrm{Wm}^{-2}\right)$. Both the latent and sensible heat fluxes are greater by approximately $16 \%$ in the coupled simulation, but the latent heat flux is one order of magnitude greater than the sensible heat flux.

After four days, the cumulated Meso-NH momentum fluxes reaches $0.2 \mathrm{~m}^{2} \mathrm{~s}^{-2}$, whereas the re-analysis gives $0.12 \mathrm{~m}^{2} \mathrm{~s}^{-2}$. This is probably due to the difference between the re-analyzed and the simulated winds mentioned in the previous Section.

At this point of the intercomparison, two comments can be made. The similarity of the surface fluxes in the forced and coupled atmospheric simulations shows the weak atmospheric response to SST forcing on the case studied. The first explanation is the good quality of the SST re-analysis, due to the large amount of data available. The oceanic feedback is already included in the SST used for the forced simulation. Another hypothesis is the importance of the large scale forcing compared to the mesoscale SST forcing in the chosen atmospheric situation. An anticyclonic situation, with a weak horizontal advection imposed by the large scale would seem more appropriate to investigate the response of the MABL to oceanic forcing (Giordani et al., 1998). The comparison of the two oceanic simulations reveals stronger fluxes for the coupled simulation, by $50 \mathrm{Wm}^{-2}$ for the cumulated net heat flux. The difference between the two simulations is the atmosphere seen by the oceanic model: re-analyzed (forced simulation) or simulated by the mesoscale atmospheric model (coupled simulation). The main difference between the two is the stronger Méso-NH winds, as mentioned in Section 3. The latent heat flux explains 40 of the $50 \mathrm{Wm}^{-2}$ difference. In addition to the stronger winds in spatial average, Méso-NH simulates spatiotemporal fluctuations of the wind that are not present in the re-analyzed 
fields, due to the lack of temporal resolution (every $6 \mathrm{~h}$ ). The evaluation of the impact of these fluctuations requires a comparison of the 2-D surface fluxes fields.

\subsection{Spatial flux comparison}

There is no doubt that the evolution of the sea surfacetemperature in response to the surface forcing is a key point to investigate coupled processes at the oceanatmosphere interface. For the two oceanic simulations, the SST cooling and the cumulated net heat flux after four days are plotted Fig. 8 and the SST field averaged over the four days has been superimposed. The 2-D fields are plotted over the part of the domain which is not affected by the horizontal relaxation at the lateral boundaries.

The stronger SST cooling for the coupled simulation is clearly apparent, but for the two simulations, the cooling is not uniform over the domain (from 0 to about $-1^{\circ}$ ). Two areas of maximum cooling can be isolated. The first one is in the south-eastern part of the domain (around $22^{\circ} \mathrm{W}, 33^{\circ} \mathrm{N}$ ) with a maximum cooling of about $-1^{\circ}$ for the two simulations. Maximum cooling also occurs in the western part of the domain $\left(25^{\circ} \mathrm{W}, 34^{\circ} 5 \mathrm{~N}\right)$, but the simulated cooling is slightly more intense.

The area of stronger cooling in the southeastern part of the domain coincides fairly well with strong net heat fluxes (respectively 250 and $320 \mathrm{Wm}^{-2}$ for the forced and coupled simulations). However, the points of maximum heat flux and maximum cooling are shifted (maximum cooling occurs about $50 \mathrm{~km}$ south of the point of maximum net heat flux). Besides, in the other area of strong cooling, in the western part of the domain, the net heat flux is rather low in both simulations (approx $175 \mathrm{Wm}^{-2}$ ). This indicates that the surface fluxes are not directly responsible for the cooling in that case. The re-analyzed SST fields (not shown here) indicate that this cooling in the western part of the simulation domain can be explained by a displacement of the oceanic front. Within four days, colder water has replaced the original warm water by Ekman transport (Caniaux and Planton, 1998). The spatial distribution of cooling and net heat flux are far from being fully correlated. It confirms that the surface
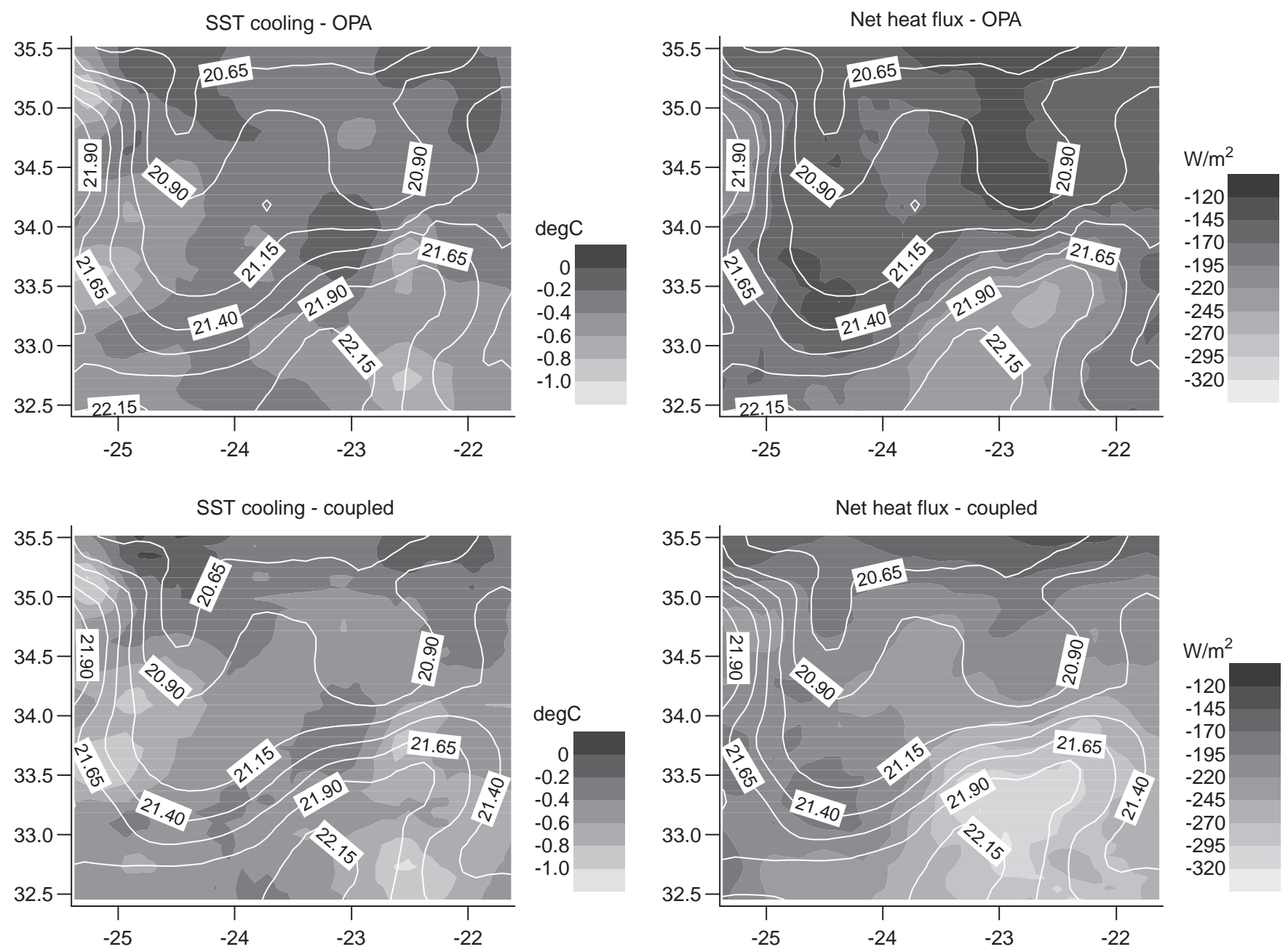

Fig. 8. Shading: SST cooling between 28 October and 1 November (left $)$ and cumulated net heat flux over the same period (right). Isolines: Average SST field. Forced oceanic simulation (top) and coupled simulation (bottom) 
fluxes can not explain alone the SST cooling during the storm. The heat budget over the oceanic mixed layer will be studied in a following paper to discuss the processes that drive the spatial distribution of the cooling.

On the other hand, the average SST field and the cumulated heat flux field show very similar structures in the two simulations. The connection between the warm water and strong heat flux zones is striking. For instance, the two tongues of cool water delimited by the $20.9^{\circ}$ isotherm in the northern part of the domain are visible on the heat flux field. The area of warm water $\left(>21.4^{\circ}\right)$ delimited by the meander of the Azores front in the southeastern part of the domain also shows strong heat flux. This high correlation comes partly from strong impact of the sea surface temperature on the net infrared flux. Still, the SST field and the (net heat flux minus net infrared flux) field are in good agreement (not shown here), with stronger fluxes over warm water south of the front and lower fluxes over cold water north of the front. The mean temperature $20 \mathrm{~m}$ above the sea surface decreases from $18^{\circ}$ to $16{ }^{\circ} \mathrm{C}$ during the first day and then increases to reach $20^{\circ} \mathrm{C}$ at the end of the simulation (Fig. 3), while the ocean turns colder from $21.6^{\circ}$ to $21{ }^{\circ} \mathrm{C}$ (Fig. 5). This implies that the ocean is warmer than the MABL during all the simulation. On average during the four days, the atmosphere is also warmer in the southern part of the domain. However, the amplitude of this atmospheric thermal contrast (imposed by the large scale) is smaller than the SST signature of the Azores front. The ocean-atmosphere temperature difference is thus maximum above the warm water south of the front.

The differences of wind, ocean-atmosphere thermal contrast $\left[\Delta\left(S S T-T_{a}\right)\right.$, hereafter thermal contrast], and total heat heat flux between the coupled and forced oceanic simulations (coupled minus forced) have been temporally averaged and plotted with the SST difference after four days (Fig. 9).

The maximum wind difference is generated by strong cyclonic winds on 31 October, when the center of the depression skims the northeastern corner of the domain. Meso-NH simulates a more pronounced pressure low and more intense convection in this area. The difference of thermal contrast comes mostly from the atmospheric temperature, as indicated by the comparison of the $20-\mathrm{m}$ temperature and SST differences (not shown). In the coupled simulation, the stronger convection in the northeastern part of the domain warms up the low atmosphere, whereas the air temperature is cooler in the southern part of the domain.

Both the differences of wind and the thermal contrast are needed to understand the net heat flux difference between the two simulations. The spatial distribution of the heat flux difference is mostly driven by the wind. However, this action of the wind is modulated by the thermal contrast.

For instance, in the northeastern corner of the domain, the flux difference is rather low in spite of a strong wind difference. The variation of the thermal contrast between the two simulations is negative (i.e. less difference between SST and atmosphere in the coupled simulation than in the forced simulation) and tends to lower the heat flux and therefore opposes the effect of the stronger wind. In the southern part of the domain, towards $23^{\circ} \mathrm{W}$, the wind difference is relatively low (about $1 \mathrm{~ms}^{-1}$ ). The strong flux variation is due to a positive anomaly of the thermal contrast (more than $0.5^{\circ}$ ).

The difference between the forced and coupled SST at the end of the four-day period is plotted on Fig. 9. The area of strong SST variation is delimited by the $-0.15^{\circ}$ isotherm. Even though the northern limit of this area seems to be correlated with the heat flux difference in the western part of the domain, there is an area with little SST difference and strong heat flux difference around $22^{\circ} \mathrm{W}, 34.5^{\circ} \mathrm{N}$.

Along the $23^{\circ} 2 \mathrm{~W}$ meridian, the heat flux difference remains greater than $75 \mathrm{Wm}^{-2}$ between $33^{\circ} 5 \mathrm{~N}$ and $34^{\circ} \mathrm{N}$. However, the SST difference after four days reaches $0.25^{\circ} \mathrm{C}$ at $34^{\circ} \mathrm{N}$ and less than $0.1^{\circ} \mathrm{C}$ at $33^{\circ} 5 \mathrm{~N}$.

More generally, this comparison shows that the oceanic circulation in the mixed layer is different in forced and coupled modes. This internal response of the oceanic mixed layer is to be taken into account to understand the impact of coupling in terms of sea surface temperature.

\section{Conclusion}

A mesoscale coupled model has been developed, and three 4-day simulations of the storm event have been performed with the coupled model on the one hand and with the atmospheric and oceanic models in forced mode on the other hand. The bulk parametrization used to calculate the turbulent fluxes is the same in each case, which allows the intercomparison of the surface fluxes of the three simulations. The ability of the mesoscale models to reproduce the main features of the evolution of ocean and atmosphere during the simulation period has been demonstrated, although the simulated oceanic cooling $\left(0.35{ }^{\circ} \mathrm{C}\right.$ in forced mode and about $0.50{ }^{\circ} \mathrm{C}$ in coupled mode) is too weak compared to the re-analyses $\left(0.75{ }^{\circ} \mathrm{C}\right)$. The $20 \mathrm{~m}$ Méso-NH winds are appreciably stronger than the re-analyzed winds, with a difference that reaches $2 \mathrm{~ms}^{-1}$ when the winds are strongest on 30 October. However, the simulated winds prove to be in better agreement than the re-analyzed winds with in situ observation (MARISONDE drifters). The simulated atmospheric variables at $20 \mathrm{~m}$ are very similar in forced and coupled modes, which seems to indicate a low impact of the mesoscale oceanic forcing compared to the large scale atmospheric forcing at the lateral boundaries. The spatially averaged surface fluxes are stronger for the forced atmospheric and coupled simulations than for the forced oceanic simulation and the re-analyses. This difference appears after two days, when the winds are maxima, and is mostly due to the latent heat flux which explains 40 of the $50 \mathrm{Wm}^{-2}$ difference. By contrast, the radiative fluxes of the two atmospheric simulations are in good agreement with the METEOSAT dataset used to force the oceanic simulation, at least when spatially averaged. As for the atmospheric parameters, and for 

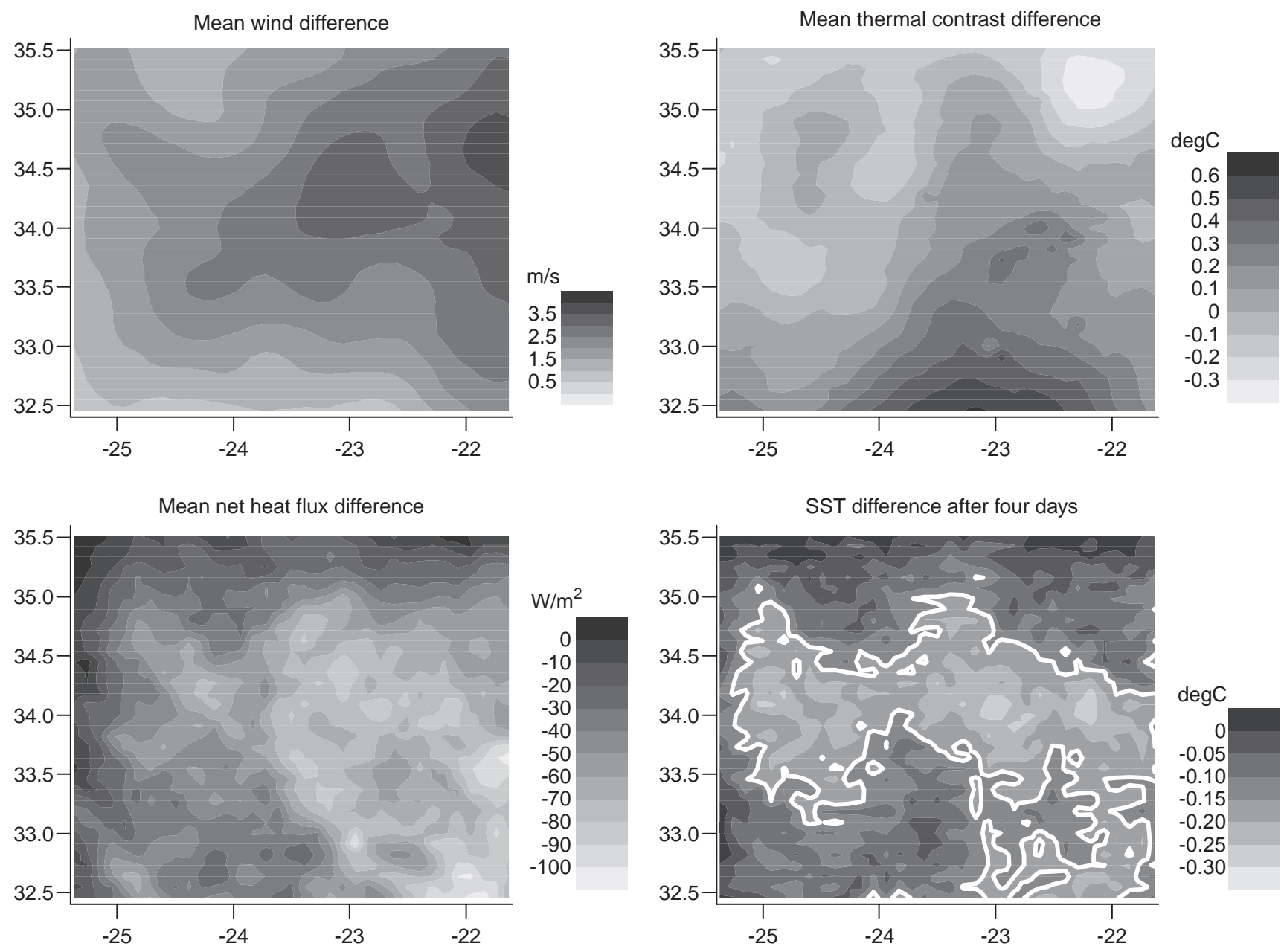

$\operatorname{deg} \mathrm{C}$

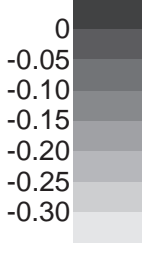

Fig. 9. From top to bottom and from left to right: wind, ocean-atmosphere thermal contrast, net heat flux and SST differences between the coupled and forced oceanic simulations

the same reasons, there is little difference between the surface fluxes of the forced and coupled atmospheric simulations.

The spatial distribution of the SST cooling is very inhomogeneous, with values that range from $0^{\circ}$ to $-1{ }^{\circ} \mathrm{C}$. In the same way, the cumulated net heat flux ranges from $-120 \mathrm{Wm}^{-2}$ to $-300 \mathrm{Wm}^{-2}$ in different parts of the domain. However, the cooling pattern and the net heat flux pattern are different, both for the reanalyses and the three simulations. This indicates that the surface fluxes are not responsible for the whole cooling. The oceanic response to atmospheric forcing is basically non local. Horizontal and vertical processes in the oceanic mixed layer are probably involved in the spatial distribution of the oceanic cooling in response to the surface fluxes. On the other hand, the correlation between the area of stronger fluxes and the warm water delimited by the meander of the Azores front is striking. The sea-air temperature difference remains positive all over the domain during all the simulation and is maximum above the warm water south of the front. The spatial distribution of wind speed, $T_{S}-T_{\text {air }}$ and net heat flux variations are needed to understand the SST difference in the forced and coupled simulation.
To go further, a better understanding of the internal oceanic response to atmospheric forcing is needed. For this purpose, oceanic diagnostics such as heat or momentum budgets over the oceanic mixed layer have to be developed and implemented in the coupled model. Sensitivity experiments would be useful to understand why the simulated SST is too warm compared to observations and to evaluate the impact of spatiotemporal mesoscale wind fluctuations on the momentum budget at the ocean-atmosphere interface.

In this paper, the atmospheric situation chosen for the simulation led us to focus on oceanic processes. Giordani et al. (1998) found that the atmospheric response to SST forcing can be strong in anticyclonic conditions. A complementary approach could be to use the coupled model to simulate a situation in which the atmospheric response to mesoscale SST forcing would be more likely to be brought to the force.

\section{References}

Adamec, D., and R. L. Elsberry, Response of an intense oceanic current system to cross-stream cooling events. J. Phys. Ocean$o g r .$, 15, 273-287, 1985a. 
Adamec, D., and R. L. Elsberry, The response of intense oceanic current systems entering regions of strong cooling. J. Phys. Oceanogr., 15, 1284-1295, 1985b.

Andrich, P., P. Delecluse, C. Levy, and G. Madec, A multitasked general circulation model of the ocean. In: Science and Engineering on Cray Supercomputers. Proceedings of the Fourth International Symposium, Minneapolis, Minnesota, October 1988, A Cray Research Inc. book, 407-428, 1988.

Bane, J. M., and K. E. Osgood, Wintertime air-sea interaction processes across the Gulf Stream. J. Geophys. Res., 15, 1284 $1295,1989$.

Blanke, B., and P. Delecluse, Low frequency variability of the tropical ocean simulated by a general circulation model with mixed layer physics. J. Phys. Oceanogr., 23, 1363-1388, 1993.

Brisson, A., P. Le Borgne, A. Marsouin, and T. Moreau, Surface irradiances calculated from METEOSAT sensor data during SOFIA-ASTEX. Int. J. Remote Sensing, 15, 197-203, 1994.

Brisson, A., P. Le Borgne, and A. Marsouin, Proceedings of the 1996 metorological satellite data users conference Vienna Austria 16-20 Sept 1996, 229-238.

Caniaux, G., and S. Planton, A 3D Ocean Mesoscale simulation using data from the SEMAPHORE Experiment, Mixed Layer Heat Budget. J. Geophys. Res., 103, C11, 25081-25099, 1998.

Caniaux, G., H. Roquet, and S. Planton, A 3D mesoscale simulation of the ocean using data from the ATHENA 88 field experiment, J. Mar. Systems, 4, 197-216, 1993.

Caniaux, G., P. Josse, and S. Planton, Sensibilité de la couche de mélange océanique aux paramétrisations physiques, Actes des Ateliers de Modélisation de l'Atmosphère, Toulouse Dec. 1996, 15-19, 1996

Carpenter, K. M., Note on the paper, Radiation conditions for lateral boundaries of limited area numerical models. $Q$. J. R. Meteorol. Soc., 110, 717-719, 1982.

Cuxart, J., P. Bougeaut, and J. L. Redelsperger, Turbulence closure for a non-hydrostatic model, In: 77th AMS Symposium on boundary layers and Turbulence, AMS, 409-412, 1995.

Davies, H. C., A lateral boundary formulation for multilevel prediction models. Q. J. R. Meteorol. Soc., 102, 405-418, 1976.

Doyle, J. D., and T. T. Warner, Mesoscale Coastal Processes during GALE IOP2, Mon. Wea. Rev., 118, 283-308, 1990.

Dupuis, H., P. K. Taylor, A. Weill, and K. Katsaros, The inertial dissipation method applied to derive turbulent fluxes over the ocean during the SOFIA/ASTEX and SEMAPHORE experiments with low to moderate wind speeds, J. Geophys. Res., 102, C9, 21115-21129, 1997.

Eymard, L., S. Planton, P. Durand, Y. Camus, L. Prieur, P. Y. Le Traon, B. Lesquere, J. Pelon, A. Weill, D. Hauser, J. Rolland, F. Baudin, B. Bénech, J. L. Brenguier, G. Caniaux, P. DeMey, E. Dombrowski, A. Druilhet, H. Dupuis, B. Ferret, C. Flamant, P. Flamant, F. Hernandez, D. Jourdan, K. Katsaros, D. Lambert, J. M. Lefèvre, P. LeBorgne, A. Marsouin, H. Roquet, J. Tournadre, V. Trouillet, and B. Zakardjian, Study of the air-sea interactions at the mesoscale, the SEMAPHORE experiment. Ann. Geophysicae, 14, 986-1015, 1996.

Friehe, C. A., W. J. Shaw, D. P. Rogers, K. L. Davidson, W. G. Large, S. A. Stage, G. H. Crescenti, S. J. S. Khalsa, G. K.
Greenhut, and F. Li, Air-Sea Fluxes and Surface Layer Turbulence Around a Sea Surface Temperature Front, J. Geophys. Res., 96, 8593-8609, 1991.

Giordani, H., S. Planton, B. Benech, and B. H. Kwon, Atmospheric boundary layer response to sea surface temperatures during the SEMAPHORE experiment. J. geophys. Res., 103, C11, 25047-25060, 1998.

Huang, R. X., A Mesoscale Planetary Layer Numerical Model for Simulations of Topographically Induced Circulations. Ph.D. Dissertation, North Carolina State University, 1990.

Josse, P., G. Caniaux, and S. Planton, Introduction de mélange diapycnal dans un modèle $1 \mathrm{D}$ de couche de mélange océanique, Actes des Ateliers de Modélisation de l'Atmosphère, Toulouse Dec. 1996, 139-143, 1996.

Kain, J. S., and J. M. Fritsch, Convective parametrization for mesoscale models, the Kain-fritsch scheme, in: Meteorol. Monogr. ed 46, K. Emmanuel ed. AMS, 165-170, 1993.

Kessler, E., On the distribution and continuity of water substance in atmospheric circulation, Meteorol. Monogr. 10, 32, 1969.

Khalsa, S. J. S. and G. K. Greenhut, Atmospheric Turbulence structure in the vicinity of an oceanic front. J. Geophys. Res., 94, 4913-4922, 1989.

Kwon, B. H., B. Benech, D. Lambert, P. Durand, A. Druilhet, H. Giordani, and S. Planton, Experimental study of MABL variability over an oceanic thermal front in the Azores Bassin, SEMAPHORE experiment. J. Geophys Res., 103, C11, 25159-25180, 1998.

Lafore, J. P., J. Stein, N. Asencio, P. Bougeault, V. Ducrocq, J. Duron, C. Fisher, P. Héreil, P. Mascart, V. Masson, J. P. Pinty, J. L. Redelsperger, E. Richard, and J. Vil-Guerau de Arellano, The Meso-NH Atmospheric Simulation System. Part I, Adiabatic formulation and control simulations. Ann. Geophysicae, 16, 90-109, 1998.

Large, W. G., J. C. McWilliams, and S. Doney, Ocean vertical mixing, a review and a model with a nonlocal boundary layer parameterization. Rev. Geophys., 32, 4, 363-403, 1994.

Morcrette, J. J., Physical parametrization of the ECMWF Model, ECMWF, Reading 1989.

Nof, D., On the response of ocean currents to atmospheric cooling. Tellus, Ser. A, 35, 60-72, 1983.

Pollard, R.T., The Joint Air-Sea Interaction Experiment-JASIN 1978. Bull Amer. Meteor. Soc., 59, 1310-1318, 1978.

Stage, S. A., and R. A. Weller, The Frontal Air-Sea Interaction Experiment (FASINEX), I, background and scientific objective. Bull. Amer. Meteor. Soc., 66, 1511-1520, 1985.

Sweet, W., J. Kerling, R. Feet, and P. La Violette, Air-sea interaction effects in the lower troposphere across the north wall of the gulf stream. Mon. Wea. Rev., 109, 1042-1052, 1981.

Terray, L., S. Valcke, and A. Piacentini, The OASIS Coupler User Guide Version 2.2, Tech. Rep. TR/CMGC/98-05, CERFACS, 1998.

Weller, R. A., D. L. Rudnick, N. J. Brink, Meteorological variability and air-sea fluxes at a closely spaced array of surface moorings. J. Geophys. Res, 100, 4867-4883, 1995.

Yelland, M. J., and P. K. Taylor, Wind stress measurements from the Open Ocean, J. Phys. Oceanogr., 26, 541-558, 1996. 